\title{
A STOCHASTIC LEARNING MODEL OF MIGRATION
}

\author{
John G. CROSS* \\ University of Michigan, Ann Arbor, MI 48109, U.S.A.
}

Received March 1977, tevised version received November 1977

It is observed in this paper that although the Harris-Todaro theory is intended to provide insigl. into rural-urban migration, their formal model describes a theory of equilibrium population densities, and although this ban be used for comparative static analyses, it is not inomediately applicable to the disequilibrium dynamic process whereby' these densities change over time. A very simple stochastic (Markov) choice model found in the psychological adaptive learning literature is applied to the migration problem, and it is found that a dynamic equation similar to that used by Todaro can be obtained explicitly from this model. The possibility that rnigration rates might accelerate even in the presence of constant urban-rural wage differentials is derived.

\section{Introduction}

In the growing literature concerning beizavioral, adaptive, or otherwise nontraditional theories of consumer and firm behavior, a great deal of stress is placed upon the need for models which are as effective in describing raarkets which are out of equilibrium as the traditional optimization theory is in describing comparative static equilibria. ${ }^{1}$ Although most of the models which are developed in this vein are indeed well-defined under conditions of incomplete

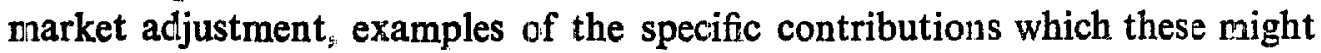
nake to particular economic problem areas are not plentiful. The purpose of this note is to make one such applicarion, using a simple stochastic learning model to support a. theory of rural-urban labor force migration, particularly is it occurs in less-developed $c r$ intries.

The comparative-static theory of labor-fo:ce location is straightforward. In most papers [such as Todaro (1969), Harris-Todaro (1970), Stiglitz (1974)] it is maintained that the urban labor supply in les j-developed countries is deterr ined not by the prevailing wage rate alone, but by a composite of the urben wagt: and the (typically high) urban unemployment rate. Individual workers are assi med

\footnotetext{
*Although the theory described bere is quite different, this note was originally stimnlated by a suggestion by $O$. Onyemelukwe to the effect that $\Sigma$ learning prois iss may underlie village attempts to receive ir zome by exporting labor to urtan areas. I would also like to hank Richard C. Porter for comments on an earlier draft.

${ }^{2}$ See, for example, tiae papers found in Day' and Groves (1975), and the references th srein.
} 
to compare the inconne which they can earn from employment in rural agriculture to that which could be received in the city, where the expected urban income is computed from the higher urban wage and various assumptions regarding the probability of finding employment there.

In the cases of the Todaro and Harris-Todaro papers, however, a good deal of stress is placed upon the importance of the dynamic process of migration itself. Todaro, for example, presents as his main hypothesis the relation

$$
\frac{\dot{S}(t)}{S(t)}=F\left[\frac{V_{u}(t)-V_{r}(t)}{V_{r}(t)}\right],
$$

where $S$ is the size of the urban labor force and $S$ its time derivative, $\left.V_{i d} t\right)$ is the discounted present value of expected urban income, and $V_{r}(t)$ is the discounted present value of expected rural income. The Harris-Todaro paper $(1970$, p. 126) similarly draws attention to migration as an ongoing phenomenon with the introductory observation that 'migration not only continues to exist, but indeed, appears to be accelerating.'

Despite these suggestions that the central problem of migration is its persistence, possibly reflecting a continuing dynamic adjustment process, even these papers revert to the simple comparative-static model in order to produce their main results. In the Harris-Todaro paper, models are formulated in which the expected urban wage is made equal to the rural wage (that is, in which migration would be zero), and the resulting equilibrium urban unemployment rate is investigated in the light of various tax and minimum wage policiss. Even the original Todaro paper concentrated upon a state in which migration is zero except for an 'equilibrium' amount which is calculated by dividing the rate of urban job creation by the employment rate and then subtracting the rate of natural urban population growth.

This reluctance to work with the migration phenomenon itself may be attributable to the fact that dynamic models such as eq. (1), plausible as they certainly are, are not derived from any formal theory, but are simply stated as initial hypotheses. The observation that a rational household must take account of the presence of unemployment in the city, and thus must compare rural income to an expected value for urban income can only be used to derive an equilibrium model for which migration is zero when the returns from the two alternatives are equal. It canrot be used to explain a stable rate of migration when the returns are unequal. Ordinary rates of migration can only occur if many individuals who could migrate do not do so even if the expected urban wage substantially exceeds the rural wage. Of course, a variety of independent viriables come immediately to mind which could be used to account for this sluggishness (and many of these play an important role in econometric studies of migration), but none of them are introduced explicitly into the theory. As it stands, eq. (1) states, in effect, that migration decisions are besed upon a 
rational comparison of income alternatives, but that a large fraction of the population irrationally fails to act on this comparison. 'That the size of this fraction should vary inversely with the difference between $V_{u}$ and $V_{r}$ is plausible, but it is nowhere explained by the theiry itself. In short, optimization theory, not being defined for disequilibrium, is simple inadequate to the task.

\section{Learning}

It is proposed in this paper that we investigate the mechanism of migration in terms of the dynamic learning paradigm which psychologists have long employed as a foundation stone for their models of human behavior. Models derived frorn this theory have the advantage of being dynamic by nature and thus of requiring no adaptation to disequilibrium circumstances. Moreover, they enjoy enough experimental support already to give us confidence that they do' in fact reflect our best available understanding of behavior change. For our purposes here, we shall apply one of the simplest of these models: that due to Bush and Mosteller as described in Cross (1973). The approach implied in these theories is entirely behaviorist in that 'decisions' of individuals are treated as random (Markov) variables whose likelihoods are dependent upon each individual's own previous experience and not upon any kind of explicit expected income or utility calculations. The variables are therefore similar in spirit io those found in sample survey studies of migration, ${ }^{2}$ except that we will not use migration probabilities as the dependient variables but focus instead upen a worker's choice of location: the individual worker, $i$, will be found in the urban sector during period $t$ with a protability $P_{t}^{i}$ and in the rural sector with a probability $1-P_{g}^{i}$. The value of $F_{i}^{i}$ is determined from experience, and there is no presumption that the worker 'knows' anything about the market beforehand.

In this regard, learning models address the problem of uncertainty (in this case the uncertainty of employment in the city) in quite an unconventional way. Traditional maximization approaches require that uncertainty be handled with statistical estimation and search procedures, many of which employ quite sophisticated techniques. ${ }^{3}$ In some cases, these even demand some prior information as to the probability distributions which characterize a maricet. Whereas optimization models therefore require greater and greater sophistication on the part of individual decision-makers as the importance of uncertainty grows, this learning model will make essentially the sarne assumptions ander both uncerteinty and certainty. The mathematics found in the two alteruative approaches are often similar, but the interpretations are wholly different.

Since our purpose is to focus upon the cconomic factors which may influence

${ }^{2}$ For a sumrnary of these studies, zee Todaro (1969).

${ }^{3}$ See McCall (1970) or Phelps (1970). 
migration, we will concentrate here upon the economic experience of the worker. A more general model could make similar use of variables reflecting such factors as age, education, family size, or population density in order to derive a more complete view of the migration process. For the sake of a simple model, we will characterize the objective situation as follows: There is one major urban center to which migration is possible. If worker $i$ locates himself in this city, he will find 'modern sector' employment which pays a high wage, $W_{u}$, with a probability $q_{i}$. If he fails to find such a job there still may exist various forms of marginal employment which will pay a. very low wage, $W_{0}$. If he does not live in the eity, rural employment guarantees an income of $W_{r}{ }^{4}$ In general, we have $W_{u}>W_{r}>W_{0}$. The likelihood $q_{t}$ should depend upon quite a number of variables such as the age of the worker, the length of his stay in the city, and, most important, whether or not he had a modern sector job in the previous period $t-1$. In the face of the potential complexity in determining $q_{i}$, however, it is common to assume (following Hlarris-Todaro) that jobs are distrik ted randomly, and since we are only conceried in this note with demonstrating the usefulness of a learning znodel, we will preserve this assumption. This makes $q_{i}$ equal to the employment rate itself, $E / S$, where $E$ is the number of modern sector jobs.

\section{3, Migration}

Beginning with the likelihood $P_{t}^{i}$, we use the actual experience of the individual during $t$ to modify this likelihood to a new value $P_{t+1}^{i}$. Naturally, both $P_{t}^{i}$ and $I_{t+1}^{i}$ must be bounded between 0 and 1 , and we expect $P_{t+1}^{i}$ to vary with the degree of success which is encountered at the location which is chosen. The well-known Bush-Mosteller linear learning model provides the simplest function which meets these conditions. For example, if $i$ lives in the city and finds a job, then we write

$$
P_{t+1}^{i}=P_{i}^{i}+\alpha_{i}\left(W_{u}\right)\left(1-P_{t}^{i}\right),
$$

where the function $\alpha_{i}(W)$ describes the rate of learning as a function of the reward (wage) magnitude. We emphasize that 'learning' here is not to be interpreted in the sense of 'finding out,' and that the worker is not being described as someone attempting to estimate $q_{i}$. Instead, $\alpha_{i}(W)$ simply reflects the empirical observation that actions which are met with success tend to be repeated. $\alpha_{l}(W)$ has the general properties

$$
0<\alpha_{i}(W)<1, \quad \alpha_{i}^{\prime}(W)>0, \quad \alpha_{i}^{\prime \prime}(W)<0,
$$

\footnotetext{
4We could, with no loss, distinguish a wage for the rural employment from a still lower rural unemployment wage. In keeping with the models already cited, however, we presume that all rural workers are equally employed.
} 
but: it is most convenier. here to approximate this function with the linear form $\alpha_{i}^{\prime} W+\alpha_{0}$ where $\alpha_{i}^{\prime}$ is the slope of the function $\alpha_{i}(W)$ in the vicinity of $W$.

Even though $\boldsymbol{P}_{t+1}^{i}>p_{t}^{i}$ in this example, the worker may nevertheless go Jack to the rural sector at the end of the period - that is, he quits and goes home with probability $1-P_{t+1}^{i}$. In this regard we are already departing from the properties of optimization theory. In both the Todaro and Harris-Todaro models, it is assumed that anyone who migrates to the city stays there so long as the expected urban economic opportunities are greater. In fact, however, some out-migration, even among the urban employed, is a common phenomenon in less-developed countries, and a dynamic modei ought to reflect that fact.

The value which is taken by $P_{t+1}^{i}$ depends upon whether the worker lives in the city and whether he gets a job. If the worker fails to find an urtan job, then ${ }^{5}$

$$
P_{t+1}^{i}=P_{t}^{i}+\left(\alpha_{1}^{\prime} W_{0}+\alpha_{0}\right)\left(1-P_{t}^{i}\right)
$$

If he lives in the rural sector, earning $W$, with certainty, a similar formula is applied to $\left(1-P_{t}^{l}\right)$, the probability of staying in the rural sector, and this recluces to

$$
P_{t+1}^{i}=P_{i}^{i}\left(1-x_{1}^{\prime} W_{r}-x_{0}\right)
$$

Combining (2a)-(2c) with their associated likelihoods ${ }^{6}$ and simplifying, we can obtain an expected value for $P_{t+1}^{l}$ :

$$
E\left[P_{i+1}^{i}\right]=P_{i}^{i}+c^{\prime} P_{i}^{i}\left(1-P_{i}^{i}\right)\left(W_{i}-W_{p}\right)
$$

where $W_{1} \equiv q_{i} W_{u}+\left(1-q_{i}\right) W_{0}$

If $N$ represents the total population available for urban-rural employment (essumed to be fixed for the purposes of this note), then the expected urban

${ }^{5}$ Since $W_{0}$ corresponds to all sorts of urban activities, legal or not, other than "modern sector' employment, $W \cdot$ would make $W_{0}>0$. Thus $P_{t+1}^{\prime}>P_{t}^{\prime}$ even for one who fails to find a regular job in the city (although naturally $P^{\prime}{ }_{t+1}$ is much larger for cne who is employed). Even when $W_{t}>W_{0}$, we nake $P_{t+1}^{\prime}=P_{t}^{i}$ for the jobless worker, reflecting a basic principle in the model that past behavior is what netually dutermines future behavior and not consideration of missed opportunities. In other words, the longer an unemployed worke stays in the city, the greater the likelihood that he will stay one more period. This is entircly consist nt with the proposition that the longer the worker is unemployed, the less likely h: is to stay in the city indefinitely. For further discussion of this point, see Cross (197., pp. 24i and 248).

$\left.{ }^{6} \mathrm{Eq} .2 \mathrm{2a}\right)$ applies with likelihood $\boldsymbol{P}_{\mathrm{f}} \cdot \cdot \boldsymbol{V}_{t}$.

Eq. (2b) applies with likelihood $P_{r}^{\prime}\left(1-q_{1}\right)$.

Eq. (2c) apjolies with likelihood $1-p_{t}^{\prime}$. 
population at time $t$ is given by

$$
S(t)=\sum_{i=1}^{N} P_{t}^{t}
$$

and the expected urban population at time $t+1$ is given by

$$
S(t+1)=\sum_{i=1}^{N} E\left[P_{t+1}^{i}\right]
$$

Eupected rnigration, $M(t)$, is the diffei,ence $S(t+i)-S(t)$ ard, using eq. (3), this; becomes

$$
M(t)=\sum_{i=1}^{N} \alpha_{i}^{\prime} P_{i}^{l}\left(1-P_{t}^{\prime}\right)\left(W_{i}-W_{r}\right)
$$

Finally, ascepting the Harris--Yodaro assumption that every city dweller has the same chance of employmert, $\left(q_{l}=E / S\right)$, then eq. (4) becomes

$$
M(t)=\left(W-W_{p}\right) \sum_{t=1}^{W I} \alpha_{i}^{\prime} P_{\imath}^{i}\left(1-F_{t}^{\prime}\right)
$$

Since the summation term is positive whatever the values of the individual proluatilities, this implies that $M^{\prime}(t)>0$ whenever the expected urban wage exceeds the rural wage, and this is the main proposition which we wished to obtcin.?

\section{Froperties of the migration finction}

Since the raigration model given by eq. (1) was not explicitly derived froin any underlying dynamic adjustruent: theory, there has naturally been consids rable debate over its most appropriate form. Todaro, for example, uses the size of the urban labor force, $S$, as the trase frori which to measure the rate of nigration. Zarimb/ca (1970) has objected ro this sfecification on the grounds that it is the rurcl population that provides tăe migrarts, and that therefore $(N-S)$ should be tised as the base. In fact, $\mathrm{Eq}$. (4) does not support either of these positions. In order to get a simple picture of the operation of eq. (4), let us assume

\footnotetext{
${ }^{7}$ Ixcidentally, the term $V_{r}$ in ine slenominator of the argument of (1), which is meant to restrict Todiro's function to proportio zate wage differences, has its counterpart in this. (4) and $(5)$ in the value of $\alpha_{1}{ }^{\circ}$ which, as an approximation to the slope of $\alpha_{l}(W)$, dexlines as $W$. increases.
} 
temporarily that all individuals are identical. This would make $P_{t}^{i}=S(t) / N$ for all $i$. Now eq. (5) becomes

$$
M(t)=\left(W-W_{r}\right) \alpha^{\prime}\left(1-\frac{S(t)}{N}\right) S(t)
$$

or

$$
\frac{M(t)}{N-S(t)}=\frac{S(t)}{N} \alpha^{\prime}\left(W-W_{r}\right),
$$

This formulation differs from that of both Toclaro and Zarembka in that the learning process applies to the entire pojmlation. In this model, $M(t)$ is the net summation of rural-urban migratirit and urban-rural migration, whereas Zarembka and Todaro only considered the effects of wage differentials on the rural population, presuming that those who move to the city never go back 'home.'

The migration process described by eq. (4) will eventually lead to a stable population distribution. Net migration will reach zero if $W_{i}=W_{\mathrm{r}}$ for all $i$ and the comparative static properties of an economy in such an equilibrium can be evaluated as usual. ${ }^{8}$ Even in this equilibrium, of course, many individual workers are changing location: it is only the net flow of migrants which is zero.

Finally, the functional form of eq. (4) has an important dynamic implication. For any constant value of $\bar{W}-W_{r}$, the character of the migration function is that of a logistic curve (indeed, the logistic is often characterized as 'the lyarning curve'). For small values of $P_{t}^{i}$ (equivalent to a predominantly rural population), $M(t)$ is correspondingly small. $M(t)$ is larger for larger $P_{t}^{i}$, reaching a maximum value when the population is approximately equally distributed tetween rural and urban components (that is, $P^{i}\left(1-P^{l}\right)$ is maximized when $\left.P^{i}=0.5\right) . M(t)$ falle again if the population shifts still further. Since most less-developed contries are predominantly rural, we would conclude that they are still in the rising phase of this process, and that if the values of $W_{i}-W_{r}$ are maintained at present levels, migration will not only continue, but will accelerate.

Although the quotation from Harris-Todaro given earlier conveys a recognition that an acceleration in migration may in fact be taking place, their use of an equilibrium model diverts attention away from this condition and suggests only that migration is a continuing response to diseauilibrium. The view obrained from eq. (4) is much more pessinistic. Present investment and wage policies in less-developed countries are often designed to maintain a $W-W$,

\footnotetext{
${ }^{8}$ It may be worth adding that in th: determination of $W_{1}$, one should take accourt of the fact that many urban workers are already more or less established in their jobs, so that, for them, $q_{1}$ is large, or: even equal to 1 . The unemployment rate among the resi. of tho urban population may be much higher (and $W_{l}$ correspondingly lower) than gros: employment' population figures would suggest. $W_{0}$ is an equaliy irrportant influence. The availability of marginall enoployment opportunities can raise $W_{1}$ considerably by making tire stats: of the urban unemployed bearable.
} 
differential in the face of migration. Imphasis is put upon the expartsion of urisan job opportunities as a neans of holding down unemployment despite constant of even rising urban wage rates. According to the dynamic implicalions of our learning model, such attempts to accommodate develcpment prilicies to current levels of migration are entirely hopeless; maintenance of the W'-W differential in the face of an acce erating tide of rural-urban raigrants will become a practical impossibility, and iuevitably, $W$ will, one way or another, be: driven down to $W_{p}$.

\section{Information}

Although it is not entirely in keeping with the strict behaviorism enbodied in the learning model we have used, nany readers of this paper have inquired about the possibility that sone workers are influenced by the success and failures of others. If a rural worker learns (in the sense of 'fincling out') thali an acquaintance has found high-paying urban employment, then he, too, may be mo: inclined to relocate is the city. In our notation, $P_{t}^{i}$ may be increased to some larger value $\left(P_{p}^{i}\right)^{\prime}$, where the extent of the increase is a function of the wage

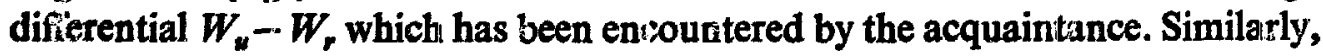
information that the acquaintance is unemployed would discourage relocallion in proportion to the wage differential $W,-W_{0}$.

If experience is the great teacher, and information of this sort is impedec by pcor information channels and widely dispersed rural populations, then this new learning is insignificant, and we can use the original model as described by $e c$. (4). If this is not the case, then we vaust introduce information flows into the original model by replacing $P_{t}^{i}$ in eq. (3) by $\left(P_{t}^{i}\right)^{\prime}$ from this second learning process. Such combined models in fa, prove to have qualitative properties which differ very little from eq. (4).

\section{References}

Cross, J.G., 1973, A stocilastic learning model of economic behavior, Quarterly Journal of Economics, 239-266.

Day, R.H. and T. Groves, eds., 1975, Adaptive ecimomic models (Academic Press, New York).

Harris, J.R., and M.P. Todaro, 1970, Migration, unemployment and development: A twosector analysis, American Economic Review 60, 126-142.

McCall, J.J., 1970, Economics of information and job search, Quarterly Journal of Econornics, $113-126$.

Phelps, E.S., 1970, Money wage dynamies and labor market equilibrium, in: E.S. Phelps, et al., Microeconomic foundationis of employinent and inflation theory, 124-166.

Stiglitz, J.E., 1974, Wage determination and unemployment in LDCs, Cuarterly Journal of Economics 88, 194-227.

Todaro, M.P., 1969, A model of labor migraticn and urban employment in less developed countries, American Economic Review 59, 13,-148.

Todaro, M.P., 1976, Internal migration in dereloping countries: A survey, INBER Conference on Population and Eonomic Change in Less Developed Countries.

Zarembica, $\boldsymbol{P}$., 1970, Labor migration and urivan vnemployment: Comment, and M.P. To.daro, Reply; American Economic Review 60, 184-188. 